\title{
PRESSURE RELIEF RADIAL PASSAGES FOR SSC ${ }^{*}$
}

\author{
Margareta L. Rehak \\ Accelerator Development Department \\ Magnet Division \\ Brookhaven National Laboratory \\ Upton, New York 11973
}

\section{INTRODUCTION}

In the $40 \mathrm{~mm}$ SSC cross--section design radial helium venting passages located every 6" were present. The purpose of these passages was to provide escape routes for helium from the coil cooling passage to the bypasses during a quench. The passages are introduced in the magnet by placing special yoke laminations with channels going from the bypasses to the inner radius.

The question as to whether the venting passages are still needed in the $50 \mathrm{~mm}$ design is addressed here. One might expect that they would be more needed here since the stored magnetic field energy increases considerably faster than the coil cooling passage cross-section, unless the width of the latter is increased.

Since the dimensions of the beam tube are not fixed at this time two cases are considered: a coil cooling passage gap of $1.3 \mathrm{~mm}$ and one of $5 \mathrm{~mm}$.

An existing computer code developed at Brookhaven National Laboratory by R.P. Shutt and programmed by $\mathrm{K}$. Jellet is applied to the present problem. The theoretical contents of the code are described in [SSC--N--266 No 59]. Pressures, helium, coil, and yoke temperatures, and mass flows are computed during a quench for one magnet with no venting occurring in the interconnect regions. Only one magnet is considered here as opposed to a string of magnets.

\section{RESULTS}

The relief passages are one lamination deep $(d=0.158 \mathrm{~cm}$ or $1 / 16 \mathrm{in}$.). However, due to limitations of the numerical method, the computer program will not run for a long enough time with this value. The conservative value $d=0.06 \mathrm{~cm}$ will be used instead. The case where there are no passages is simulated with $d=0.001 \mathrm{~cm}$.

\section{MASTER}

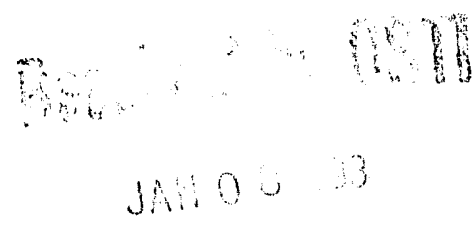

\section{DISCLAIMER}

Work supported by the U.S. Department of Energy
This report was prepared as an account of work sponsored by an agency of the United States Government. Neither the United States Government nor any agency thereof, nor any of their employees, makes any warranty, express or implied, or assumes any legal liability or responsibility for the accuracy, completeness, or usefulness of any information, apparatus, product, or process disclosed, or represents that its use would not infringe privately owned rights. Reference herein to any specific commercial product, process, or service by trade name, trademark. manufacturer, or otherwise does not necessarily constitute or imply its endorsement, recommendation, or favoring by the United States Government or any agency thereof. The views and opinions of authors expressed herein do not necessarily state or reflect those of the United States Government or any agency thereof. 
Of all the results produced by the calculations, that which is of most interest is the helium pressure around the beam tube, where the pressure is expected to be the highest. Figures 1 to 4 illustrate helium pressure (at the location where it is maximum) around the beam tube as a function of time, and the table summarizes the results. Note that the final times differ since they correspond to times where the program stops.

Table 2.1: Pressures around the beam tube.

\begin{tabular}{|l|c|c|c|c|}
\hline Coil cooling passage gap (mm) & 1.3 & 1.3 & 5 & 5 \\
\hline Relief passages & yes & no & yes & no \\
\hline Maximum pressure around beam tube (atm) & 12.6 & $29.4^{\circ}$ & $10.0^{\circ}$ & $8.5^{\circ}$ \\
\hline
\end{tabular}

(" pressure still rising at end of time for which pressure is calculated)

Figure 1 shows that the maximum pressure around the beam tube is 12.6 atm when the relief passages are present and when the coil cooling passage gap is $1.3 \mathrm{~mm}$. In the abserice of these passages Figure 2 shows that the pressure rises to $29.4 \mathrm{~atm}$ and above which is above the $20 \mathrm{~atm}$ design pressure. If the coil cooling passage gap were $5 \mathrm{~mm}$ then Figures 3 and 4 show that the presence of relief passages has little effoct on the pressure around the beam tube. In Figures 2,3 and 4 pressures are still rising at the end of the shown time periods. However, in Fig. 2 the design pressure has already been exceeded, and at the end of the time periods in Figs. 3 and 4 vent values in interconnections would have opened, relieving the pressure fast. Concerning Fig. 2, the maximum pressure in the interconnection is only $4.5 \mathrm{~atm}$.

\section{BUCKLING PRESSURE}

These pressures should be compared with the 20 atm design pressure and the critical pressure for buckling. A formula from "Roark's Formulas for stress and strain, W.C. Young, McGraw Hill" gives the critical pressure of an extemally pressurized tube:

$$
p=\frac{t}{R} \frac{\sigma_{y}}{1+\left(\frac{4 \sigma_{y}}{E}\right)\left(\frac{R}{t}\right)^{2}}
$$

For a beam tube of radius $R=0.8$ in. $(2.0 \mathrm{~cm})$, thickness $t=0.06$ in. $(0.15 \mathrm{~cm})$ and yield strength $\sigma_{y}=30000$ psi then $p$ is equal to $1314 \mathrm{psi}(=91.8 \mathrm{~atm}(9 . \mathrm{MPa}))$. If there are no relief passages for the $1.3 \mathrm{~mm}$ gap the safety factor for the beam tube is 3 . Thus the beam tube would still be safe even while excoeding the design value of $20 \mathrm{~atm}$.

On the other hand if the shell thickness is halved then $p=292 \mathrm{psi}=20 \mathrm{~atm}$ (2 Mpa) and the beam tube will fail.

\section{CONCLUSIONS}

If the coil cooling passage gap is $1.3 \mathrm{~mm}$ as it was in the $40 \mathrm{~mm}$ design then relief passages are needed in order to remain below the design pressure of $20 \mathrm{~atm}$ for the beam tube.

For a $5 \mathrm{~mm}$ coil cooling passage gap relief passages are not needed. 


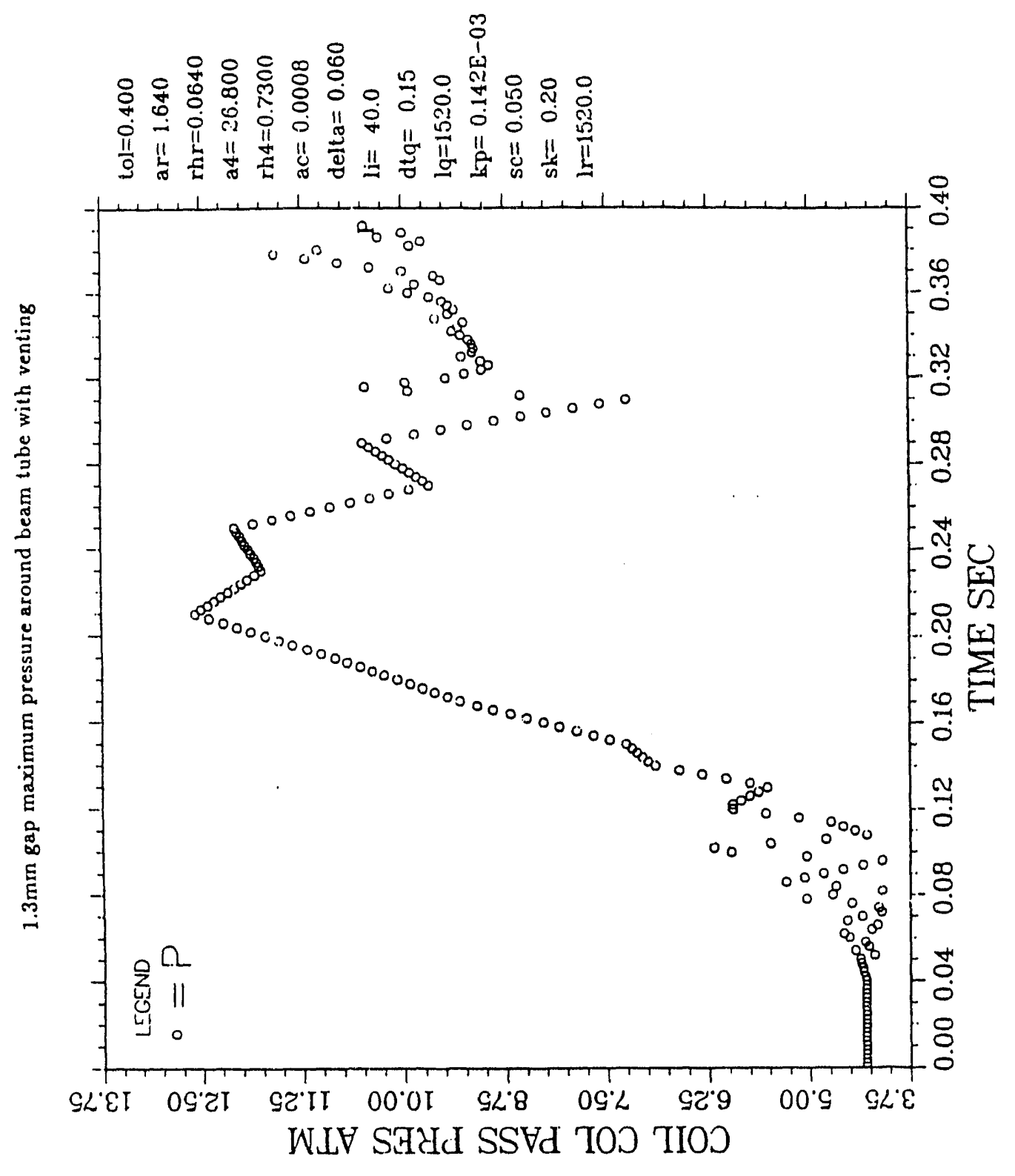

Figure 1. 


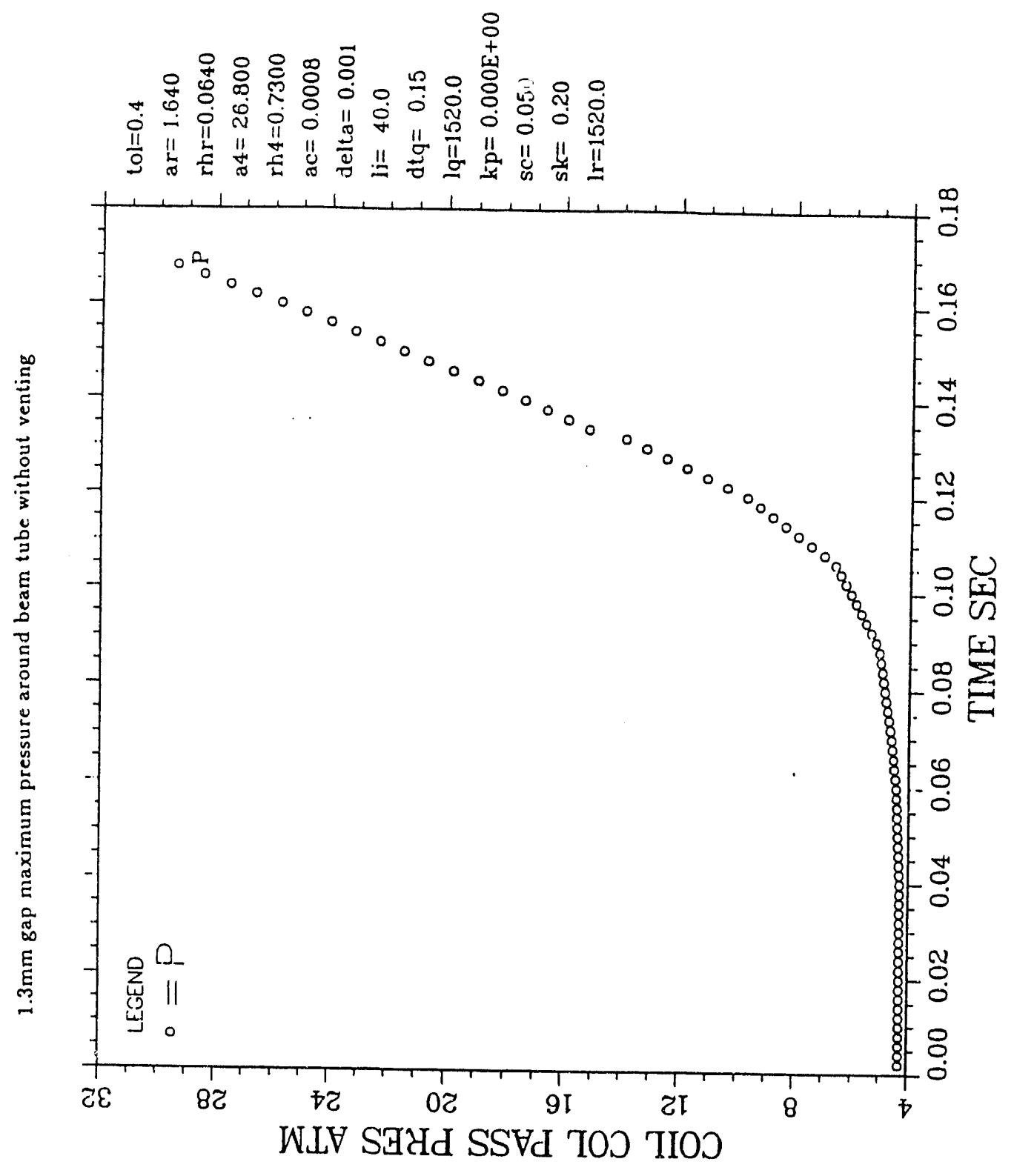

Figure 2. 


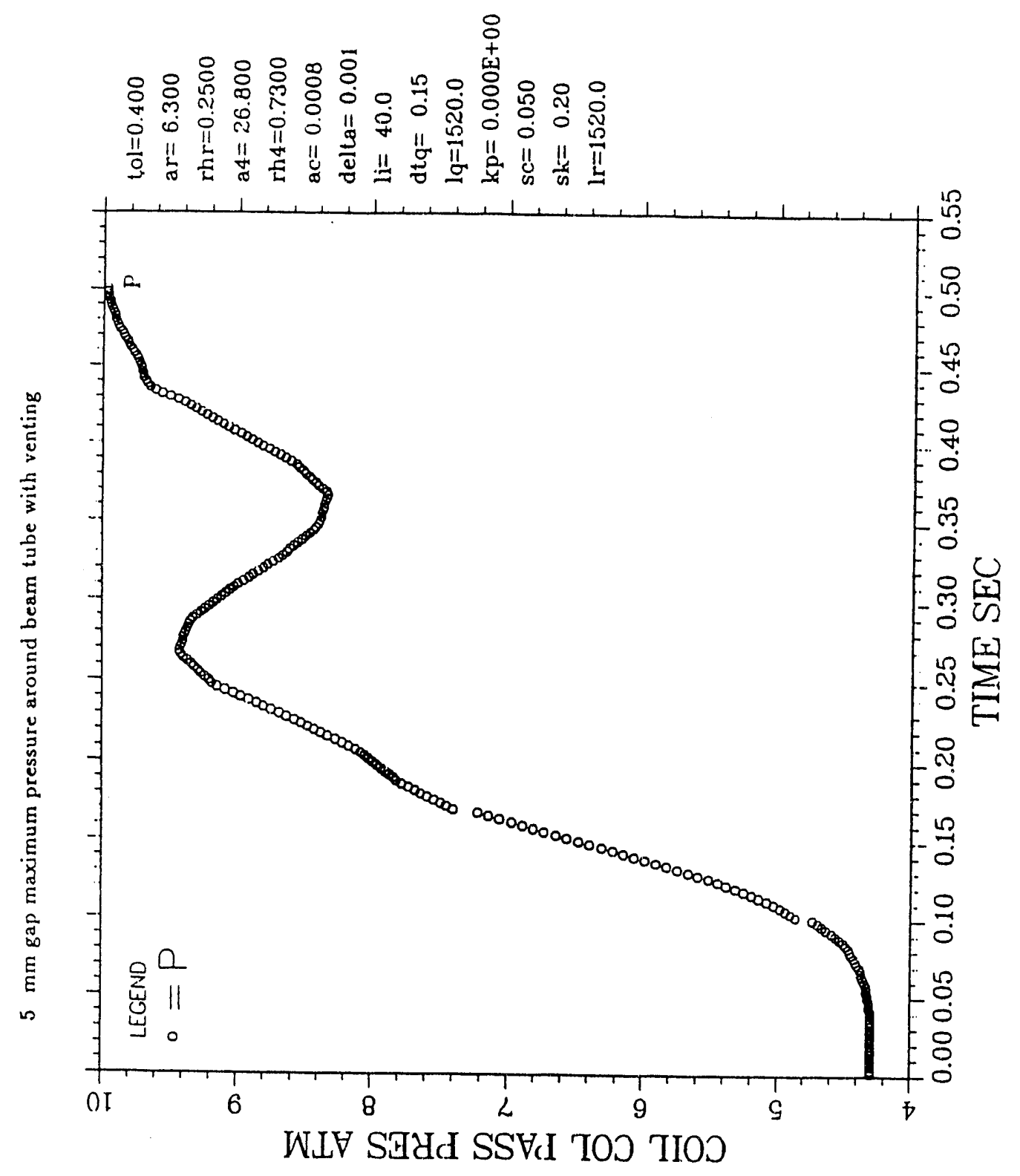

Figure 3. 


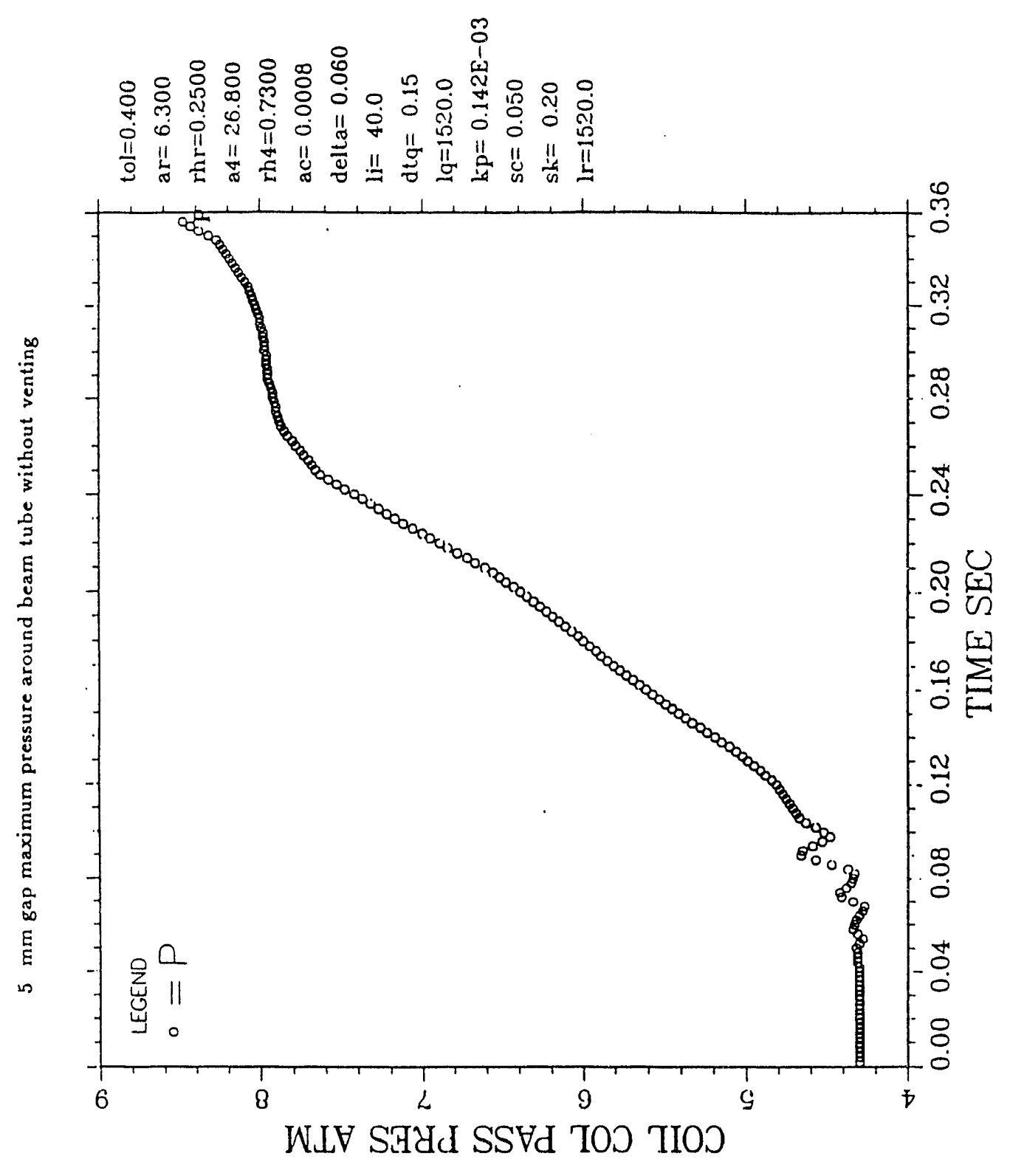

Figure 4. 

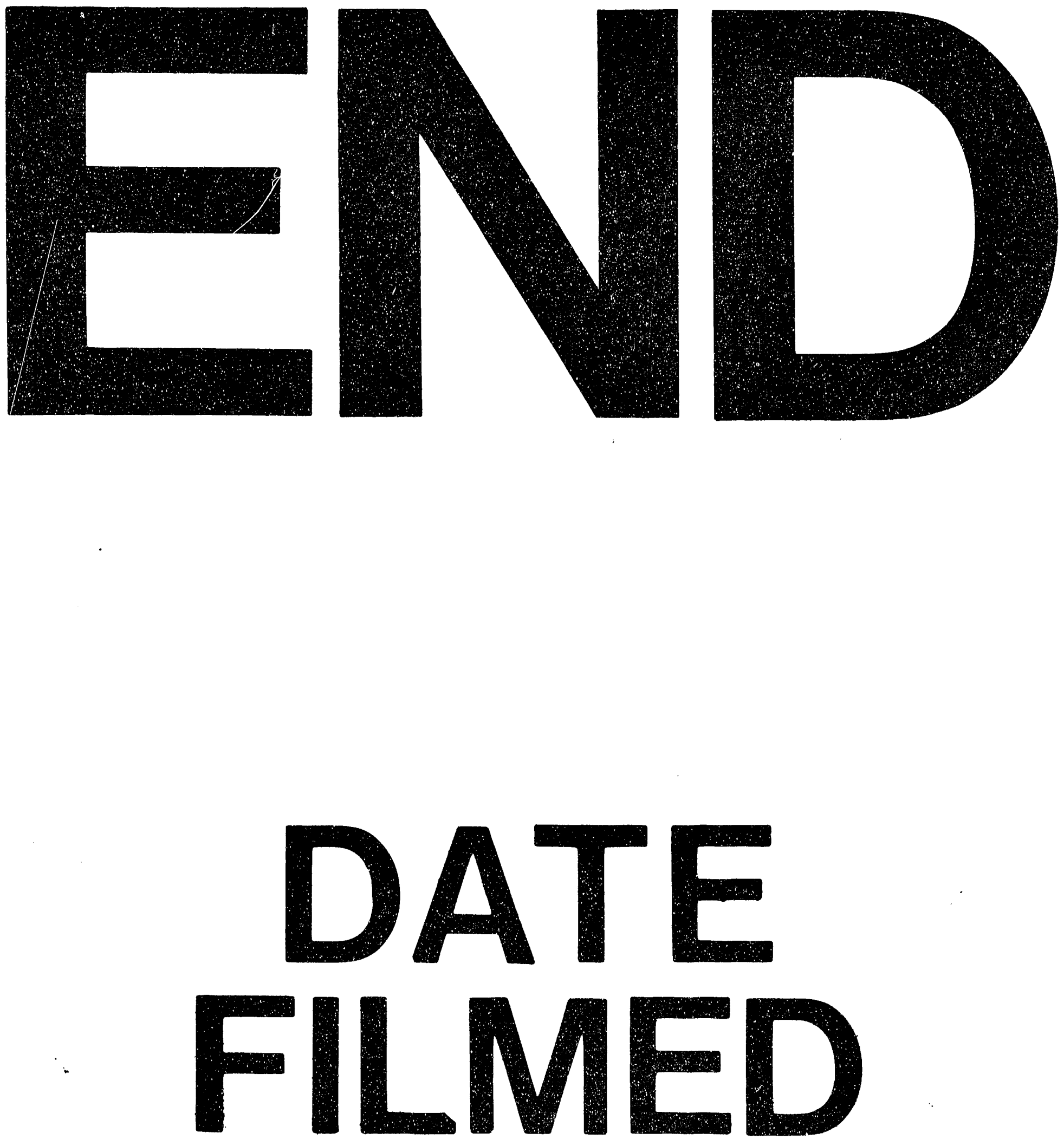

1
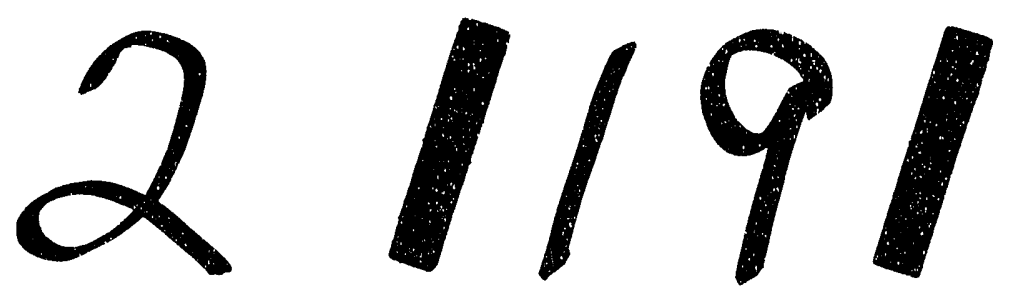

93 
